\title{
Eine Entdeckungsgeschichte
}

Erhard Taverna

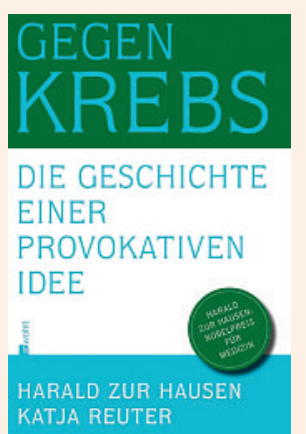

Harald zur Hausen,

Katja Reuter

Gegen Krebs

Die Geschichte einer provokativen Idee.

Berlin: Rowohlt; 2010.

352 Seiten. $37.90 \mathrm{CHF}$.

ISBN 978-3-498-03001-8

Die Geschichte einer Idee, ein Lebensprojekt, das 2008 mit dem Nobelpreis für Medizin geehrt wurde. Es gab danach Misstöne, genüsslich in den Medien breitgeschlagen, Unterstellungen neidischer Berufskollegen, Verdächtigungen von Impfgegnern und eine Untersuchung der schwedischen Staatsanwaltschaft. Alles ohne nachhaltige Folgen. Denn inzwischen hat sich die Impfung gegen humane Papillomaviren (HPV) als gut verträglich erwiesen, und weltweit sind über 61 Millionen Dosen verabreicht worden.

Von Anfang an blieb Harald zur Hausen sich selber treu. Der junge Mediziner entschied sich für die Krebsforschung, obwohl damals die Wissenschaft aus Sicht vieler Ärzte als Abstellgleis galt. Es gab Indizien für eine Verbindung von Viren und Krebs bei Tieren und Pflanzen, aber keinen brauchbaren Anhaltspunkt bei Menschen. Dann wurde das Epstein-Barr-Virus in Zellen des Burkitt-Tumors nachgewiesen, und der junge Forscher entschied Ende der 60er Jahre, die Rolle der Papillomaviren beim Gebärmutterhalskrebs

\section{«Der Zufall beglückt den vorbereiteten Geist.»}

zu untersuchen. Harald zur Hausen, geboren 1936, hat zusammen mit der Journalistin Katja Reuter 2010 seine wissenschaftliche Biografie veröffentlicht. «Wir haben dieses Buch für naturwissenschaftlich und biografisch interessierte Leser geschrieben, die sich für die Motive und Herausforderungen von Wissenschaftlern in ihrem Arbeitsalltag, aber auch für die weniger glanzvollen Seiten der Forschung, die oft im Dunklen bleiben, interessieren.» Entstanden ist ein Arbeitsprotokoll aus der Forschungspraxis, das einen ausgezeichneten Einblick in die rasante Entwicklung der Biowissenschaften der letzten vier Jahrzehnte ermöglicht. Elektronenmikroskopie, radioaktive Markierungen, Restriktionsenzyme, DANN-Gel-Elektrophorese und PCR, ein gutes Laborteam, aufwendige Kleinarbeit, unendliche Ausdauer und eine internationale Vernetzung sind einige wenige Stichworte zum Verständnis der wissenschaftlichen Methodik. Harald zur Hausen begann seine Forschung mit Herpesviren, die irrtümlich lange Zeit als Hauptverdächtige galten.

Er studierte erst Leukämiezellen und Adenoviren und entdeckte mit seinen Kollegen die Ursache der infektiösen Mononukleose, bevor ihnen 1983 erstmals der Nachweis von DNA eines Papillomavirus in einem Gebärmutterhalstumor gelang. Im gleichen Jahr fand sein Team Erbmaterial der Papillomaviren vom Typ 16 und 18 auch in Krebsvorstufen, die nun als Hoch-Risiko-Typen eingestuft wurden. Erstmals wurde die Entwicklung eines Impfstoffes mit Hilfe pharmazeutischer Firmen diskutiert. 1992 wurden die Grundlagen für den Impfstoff Gardasil geschaffen, den die FDA 2006 genehmigte, 2007 wurde Cervarix in Australien lizenziert und von der EU als zweiter Impfstoff zugelassen. Harald zur Hausen hat sich stets dafür eingesetzt, dass auch negative Ergebnisse in Fachmagazinen wie zum Beispiel dem «Journal of Negative Results in BioMedicine» publiziert werden. Öffentlich ausgetragene Auseinandersetzungen, Kritik und Skepsis, Ablehnung und Sabotage, Konkurrenz um Finanzen, der Wettlauf um eine Publikation, Irrwege und falsche Lehrmeinungen, Tiefpunkte und offene Ablehnung, nichts bleibt unerwähnt. «Der Zufall beglückt den vorbereiteten Geist» soll Louis Pasteur gesagt haben, die Kunst besteht darin, die richtigen Schlüsse zu ziehen. Von 1983 bis 2003 leitete Harald zur Hausen als Vorsitzender des Stiftungsvorstandes das deutsche Krebsforschungszentrum in Heidelberg. 2008 erhielt er hälftig den Nobelpreis für Physiologie oder Medizin, zusammen mit den AidsForschern Barré-Sinoussi und Montaigner. Der Vorwurf einer möglichen Beeinflussung des Nobelpreiskomitees durch die Firma AstraZeneca erwies sich als haltlos, die kritischen Behauptungen eines Manifests von 13 prominenten Fachvertretern des deutschen Gesundheitswesens und eine ähnliche Erklärung des Präsidenten der Berliner Ärztekammer wurden alle widerlegt.

Das Nachspiel zeigt deutlich, wie wichtig offengelegte Interessenbindungen sind. Transparenz ist ein wirksames Argument gegen die verbreitete Impfskepsis. Die deutsche Impfkommission hat ihre Verbindungen zur Industrie im Frühjahr 2008 deklariert. Im Februar 2010 gab die Eidgenössische Impfkommission, unter äusserem Druck, erstmals die Interessenbindungen der 16 Mitglieder bekannt. Harald zur Hausen ist in vieler Hinsicht ein gutes Beispiel: offen, ausdauernd, selbstkritisch, kompetent und erfolgreich. Nach seinem Vorbild wünsche ich allen Kolleginnen und Kollegen ein gutes neues Jahr. 